\title{
Auditory Predictive Coding across Awareness States under Anesthesia: An Intracranial Electrophysiology Study
}

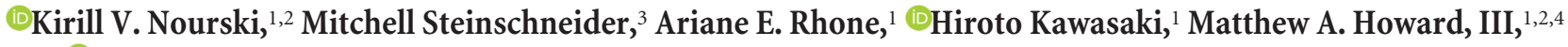 \\ and Matthew I. Banks ${ }^{5}$ \\ ${ }^{1}$ Department of Neurosurgery, ${ }^{2}$ Iowa Neuroscience Institute, University of Iowa, Iowa City, Iowa 52242, ${ }^{3}$ Departments of Neurology and Neuroscience, \\ Albert Einstein College of Medicine, Bronx, New York 10461, 4 Pappajohn Biomedical Institute, University of Iowa, Iowa City, Iowa 52242, and \\ ${ }^{5}$ Departments of Anesthesiology and Neuroscience, University of Wisconsin-Madison, Madison, Wisconsin 53705
}

The systems-level mechanisms underlying loss of consciousness (LOC) under anesthesia remain unclear. General anesthetics suppress sensory responses within higher-order cortex and feedback connections, both critical elements of predictive coding hypotheses of conscious perception. Responses to auditory novelty may offer promise as biomarkers for consciousness. This study examined anesthesia-induced changes in auditory novelty responses over short (local deviant [LD]) and long (global deviant [GD]) time scales, envisioned to engage preattentive and conscious levels of processing, respectively. Electrocorticographic recordings were obtained in human neurosurgical patients ( 3 male, 3 female) from four hierarchical processing levels: core auditory cortex, non-core auditory cortex, auditory-related, and PFC. Stimuli were vowel patterns incorporating deviants within and across stimuli (LD and GD). Subjects were presented with stimuli while awake, and during sedation (responsive) and following LOC (unresponsive) under propofol anesthesia. LD and GD effects were assayed as the averaged evoked potential and high gamma $(70-150 \mathrm{~Hz})$ activity. In the awake state, LD and GD effects were present in all recorded regions, with averaged evoked potential effects more broadly distributed than high gamma activity. Under sedation, LD effects were preserved in all regions, except PFC. LOC was accompanied by loss of LD effects outside of auditory cortex. By contrast, GD effects were markedly suppressed under sedation in all regions and were absent following LOC. Thus, although the presence of GD effects is indicative of being awake, its absence is not indicative of LOC. Loss of LD effects in higher-order cortical areas may constitute an alternative biomarker of LOC.

Key words: averaged evoked potential; consciousness; electrocorticography; high gamma; human auditory cortex; propofol

Significance Statement

Development of a biomarker that indexes changes in the brain upon loss of consciousness (LOC) under general anesthesia has broad implications for elucidating the neural basis of awareness and clinical relevance to mechanisms of sleep, coma, and disorders of consciousness. Using intracranial recordings from neurosurgery patients, we investigated changes in the activation of cortical networks involved in auditory novelty detection over short (local deviance) and long (global deviance) time scales associated with sedation and LOC under propofol anesthesia. Our results indicate that, whereas the presence of global deviance effects can index awareness, their loss cannot serve as a biomarker for LOC. The dramatic reduction of local deviance effects in areas beyond auditory cortex may constitute an alternative biomarker of LOC.

\section{Introduction}

Although the molecular and cellular effects of general anesthetics are well defined (Rudolph and Antkowiak, 2004; Franks, 2008), a

Received April 15, 2018; revised July 3, 2018; accepted Aug. 11, 2018.

Author contributions: K.V.N., M.S., and M.I.B. wrote the first draft of the paper; K.V.N., M.S., A.E.R., H.K., M.A.H., and M.I.B. edited the paper; K.V.N. and M.I.B. designed research; K.V.N., A.E.R., H.K., M.A.H., and M.I.B. performed research; K.V.N., M.S., A.E.R., and M.I.B. analyzed data; K.V.N., M.S., A.E.R., and M.I.B. wrote the paper.

This work was supported by the National Institutes of Health Grants R01-DC04290, R01-GM109086, and UL1RR024979, National Science Foundation Grant CRCNS-IIS-1515678, and the Hoover Fund. We thank Haiming Chen, Phillip Gander, Bradley Hindman, Christopher Kovach, Bryan Krause, Rashmi Mueller, Caitlin Murphy, Melissa Paul- comparable understanding of loss of consciousness (LOC) under anesthesia at a systems level is lacking. The broad implications of this question are reflected in the convergence of research into anesthesia, sleep, coma, and the neural basis of consciousness

ing, Yuri Saalmann, Beau Snoad, and Xiayi Wang for help with data collection, analysis, and comments on the manuscript.

The authors declare no competing financial interests.

Correspondence should be addressed to Dr. Kirill V. Nourski, Department of Neurosurgery, University of lowa, 200 Hawkins Drive, 1815 JCP, lowa City, IA 52242. E-mail: kirill-nourski@uiowa.edu.

DOI:10.1523/JNEUROSCI.0967-18.2018

Copyright $\odot 2018$ the authors $\quad 0270-6474 / 18 / 388441-12 \$ 15.00 / 0$ 
Table 1. Subject demographics and electrode coverage

\begin{tabular}{|c|c|c|c|c|c|c|c|c|c|c|c|c|}
\hline \multirow[b]{2}{*}{ Subject no. ${ }^{a}$} & \multirow[b]{2}{*}{ Age (yr) } & \multirow[b]{2}{*}{ Sex } & \multirow[b]{2}{*}{ Seizure focus } & \multicolumn{9}{|c|}{ Electrode coverage } \\
\hline & & & & HGPM & HGAL & PT & $\mathrm{PP}$ & STG & Auditory-related & PFC & Other & $\overline{\text { Total }}$ \\
\hline R369 & 30 & Male & Right medial temporal lobe & 8 & 5 & 4 & 6 & 20 & 77 & 44 & 51 & 215 \\
\hline L372 & 34 & Male & Left temporal pole & 6 & 4 & 4 & 4 & 25 & 56 & 34 & 48 & 181 \\
\hline R376 & 48 & Female & Right medial temporal lobe & 7 & 4 & 3 & 3 & 21 & 73 & 30 & 58 & 199 \\
\hline R394 & 24 & Male & Right amygdala & 8 & 0 & 2 & 0 & 0 & 6 & 2 & 7 & 25 \\
\hline R399 & 22 & Female & $\begin{array}{l}\text { Right temporal lobe with early propagation } \\
\text { to right inferior lateral frontal lobe }\end{array}$ & 3 & 4 & 2 & 1 & 23 & 46 & 47 & 62 & 188 \\
\hline L400 & 59 & Female & Left amygdala & 4 & 5 & 1 & 1 & 6 & 24 & 56 & 61 & 158 \\
\hline Total & & & & 36 & 22 & 16 & 15 & 95 & 282 & 213 & 287 & 966 \\
\hline
\end{tabular}

aLetter prefix of the subject code indicates the side of electrode implantation over auditory cortex and the side of seizure focus: L, left; R, right. Most subjects had, to varying degrees, bilateral coverage of other regions of the brain.

(Mashour, 2006; Alkire et al., 2008; Shushruth, 2013). Recent studies suggesting that evaluation of patients with disorders of consciousness (DOC) can be improved by incorporating noninvasive metrics of neural activity (Bayne et al., 2017; Bernat, 2017) and the need for objective measures of awareness under general anesthesia (Avidan et al., 2011) further highlights the importance of this problem.

Although general anesthetics act on subcortical sleep and arousal centers (Devor and Zalkind, 2001; Nelson et al., 2002; Långsjö et al., 2012; Zhang et al., 2015), changes in the contents of consciousness are likely secondary to effects on thalamocortical networks (Llinás et al., 1998; Dehaene and Naccache, 2001; Crick and Koch, 2003; Koch et al., 2016); however, specific mechanisms and sites of action are unclear (Nelson et al., 2002; Franks, 2008; Koch et al., 2016). Primary sensory areas are relatively resistant to LOC under anesthesia and sleep (Raz et al., 2014; Nir et al., 2015; Durand et al., 2016), whereas activity in higher-order cortex is markedly suppressed (Portas et al., 2000; Liu et al., 2012; Wilf et al., 2016), as is corticocortical, and especially feedback (FB), connectivity (Massimini et al., 2005; Ferrarelli et al., 2010; Boly et al., 2012; Raz et al., 2014). This suggests that neural correlates of LOC under anesthesia will be observed in higher-order cortex and be revealed during sensory tasks that engage cortical FB pathways (Davis and Johnsrude, 2007).

Detection of auditory novelty is postulated to activate hierarchical sensory cortical networks mediating predictive coding (Mumford, 1992; Rao and Ballard, 1999; Friston, 2005; Garrido et al., 2009). Under the predictive coding hypothesis, the brain uses a generative model to best match sensory observations wherein predictions carried by FB connections from higherorder cortex are compared with sensory-driven inputs into lower-order cortex, and prediction errors are projected to higher levels via feedforward connections (Friston, 2005; Bar, 2009; Clark, 2013). This form of bidirectional information exchange is also central to leading theories of brain function and consciousness (Friston, 2005; Dehaene and Changeux, 2011; Mashour, 2013; Tononi et al., 2016), and its disruption upon LOC would render impossible the process of Bayesian inference postulated to underlie conscious interpretation of sensory stimuli (Friston, 2005; Bastos et al., 2012).

The brain likely uses a hierarchical generative model that operates over multiple spatiotemporal scales, matching the environment characterized by nested sensory objects (e.g., phonemes, words, sentences in spoken language). The local-global deviant (LGD) paradigm is specifically designed to probe auditory predictive coding over multiple temporal integration windows by establishing prior expectations over short (local deviant, [LD]) and long (global deviant, [GD]) time scales (Bekinschtein et al., 2009). This study used the LGD paradigm to investigate the effects of propofol anesthesia on auditory predictive coding. LGD stimuli engage both preattentive and conscious perceptual processes and elicit error signals with distinct latencies and generators (Bekinschtein et al., 2009; Strauss et al., 2015). LD error signals ("effects") align with the scalp-recorded mismatch negativity (MMN) (Näätänen and Alho, 1995), thought to be primarily generated within the temporal lobe (Bekinschtein et al., 2009; Fishman, 2014; Joos et al., 2014). GD effects align with the P3b component of event-related potentials (Kok, 2001) and activate a broader cortical network (Bekinschtein et al., 2009).

GD effects have been postulated to represent a key signature of conscious processing in the global workspace theory (Bekinschtein et al., 2009; Dehaene and Changeux, 2011). These effects, which dissipate upon LOC, have been proposed as biomarkers for awareness (Faugeras et al., 2012; Strauss et al., 2015; Uhrig et al., 2016). However, these effects are suppressed by inattention (Sergent et al., 2005; Bekinschtein et al., 2009), which can occur while subjects are still conscious (Heinke and Koelsch, 2005). By contrast, LD effects, as manifested by the $\mathrm{MMN}$, are typically described as preattentive and relatively resistant to LOC (Näätänen et al., 2011) yet are also modulated by attention (Näätänen et al., 1993; Chennu et al., 2013) and awareness (Simpson et al., 2002; Strauss et al., 2015). Thus, key questions remain regarding the dependence of $\mathrm{LD}$ and GD effects on level of consciousness. Here, we tested the hypothesis that LGD effects can track changes in awareness (i.e., sedation and LOC) under propofol anesthesia, using intracranial recordings obtained simultaneously from key processing stages involved in auditory predictive coding: core and non-core auditory, auditory-related, and PFC.

\section{Materials and Methods}

Subjects. Subjects were 6 neurosurgical patients with medically refractory epilepsy (Table 1) who had been implanted with intracranial electrocorticography (ECoG) electrodes to identify resectable seizure foci (Nourski and Howard, 2015; Nourski et al., 2017, 2018). Research protocols were approved by the University of Iowa Institutional Review Board and the National Institutes of Health, and written informed consent was obtained from all subjects. Subjects could rescind their participation without interrupting their clinical monitoring. Experiments were conducted in the operating room before electrode removal and seizure focus resection surgery.

Subjects were right-handed, left language-dominant native English speakers. All subjects underwent standard audiometric and neuropsychological evaluation, and none was found to have hearing or cognitive deficits that would impact the findings of this study. Subject R394 had previously undergone a resection of a cavernoma in the anterior medial temporal lobe, which spared all ROIs in this study, except planum polare. This subject had normal hearing, cognitive abilities, and above-average task performance, justifying this subject's inclusion in the study. 


\section{A Four stimuli, each includes five 100 ms vowels [a] and [i]:}

Stimulus $1 a-a-a-a-a$

Stimulus $2 a-a-a-a-i$

Stimulus $3 \mathrm{i} \mathrm{i}-\mathrm{i}-\mathrm{i}$

Stimulus $4 \mathrm{i} \mathrm{i}-\mathrm{i}$

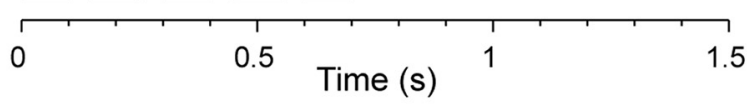

B Four sequences, each includes 100 stimuli:

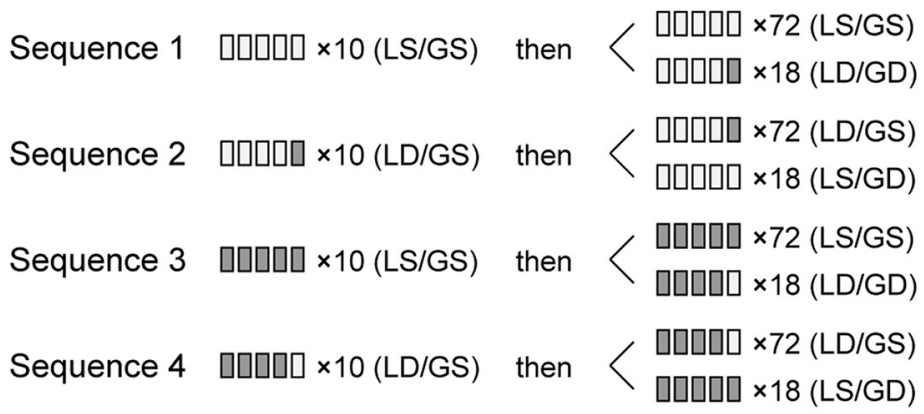

C Two levels of auditory novelty:

Local deviance effect $=$ LD - LS, i.e.

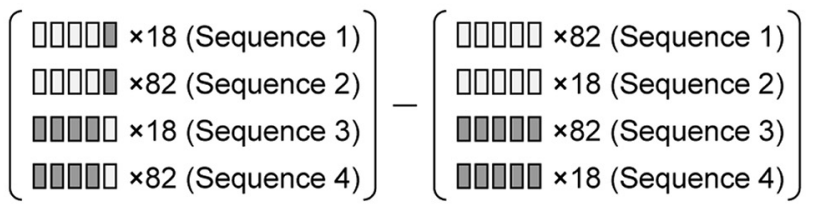

Global deviance effect $=\mathrm{GD}-\mathrm{GS}$, i.e.

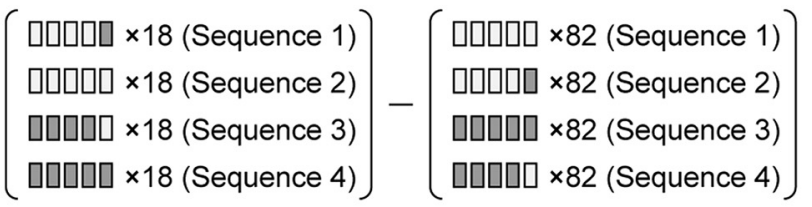

\section{Four 11-minute LGD experimental blocks:}

Propofol infusion rate $(\mu \mathrm{g} / \mathrm{kg} / \mathrm{min})$ :

\begin{tabular}{|l|l|l|l|l|l|}
\hline 0 & 50 & 75 & 100 & 125 & 150 \\
\hline
\end{tabular}

Experimental blocks (each block includes four sequences):

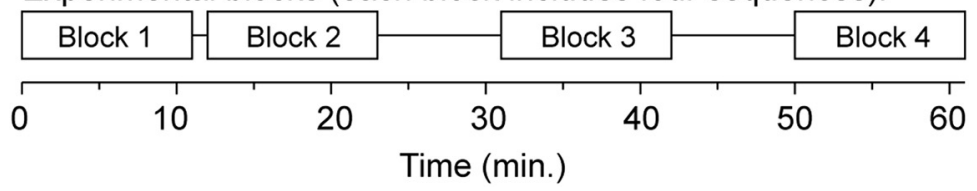

Figure 1. LD and GD experimental paradigm. $A$, Schematic of the four experimental stimuli. $\boldsymbol{B}$, Stimulus sequences. LS, Local standard. C, Comparisons between trials to characterize LD and GD effects. D, Stimulus presentation during awake baseline period and induction of general anesthesia with stepwise increases in propofol dose. Adapted with permission from Strauss et al. (2015).

Stimuli. Stimuli were vowels /a/ and /i/, presented in an LGD paradigm (Bekinschtein et al., 2009; Strauss et al., 2015) (Fig. 1). The vowels were excised from the steady-state vowel portions of syllables /had/ and /hid/, spoken by a female talker (Hillenbrand et al., 1995). On each trial, five $100 \mathrm{~ms}$ vowels, each gated with $5 \mathrm{~ms}$ on/off ramps and separated by $50 \mathrm{~ms}$ silent intervals, were presented, with the fifth vowel being either the same as the first four (local standard) or different (LD; Fig. 1A).
In each experimental block, the stimuli were presented in four sequences, with the order of the sequences randomized across blocks (Fig. $1 B)$. Subjects were asked to perform a GD target detection task by pressing a button with the hand ipsilateral to the hemisphere from which recordings were made. Each sequence began with a recorded instruction that defined the target stimulus to the subject. For example, Sequence 1 was preceded with the following instruction: "This time, press the button when you hear this sound: /aadai/. Once again, press the button when you hear this sound: /aaaai/." This was followed by 10 trials that established the global standard (e.g., /aaaad/ for Sequence 1), and then by 72 global standard trials and 18 GD trials, presented in a pseudorandom order with an intertrial interval of $1500 \pm 10 \mathrm{~ms}$ (mean, SD). The difference in presentation frequency thus constituted the global deviance, and the GD stimulus changed across the four sequences within each block (Fig. 1C). The key feature of this paradigm is that the LD stimulus can be either a global standard (as in Sequences 2 and 4) or a GD (as in Sequences 1 and 3) depending on its presentation frequency within a sequence.

Recording. ECoG recordings were made using subdural and depth electrodes (AdTech Medical). Subdural arrays consisted of platinum-iridium discs $(2.3 \mathrm{~mm}$ diameter, 5-10 mm interelectrode distance), embedded in a silicon membrane. Depth arrays (8-12 electrodes, $5 \mathrm{~mm}$ interelectrode distance) were stereotactically implanted along the anterolateral-to-posteromedial axis of Heschl's gyrus (HG). Additional arrays targeted insular cortex and provided coverage of planum temporale and planum polare. This allowed for bracketing suspected epileptogenic zones from dorsal, ventral, medial, and lateral aspects (Reddy et al., 2010; Nagahama et al., 2018). Depth electrodes that targeted amygdala and hippocampus provided additional coverage of auditory-related cortex within superior temporal sulcus. A subgaleal electrode was used as a reference. All electrodes were placed solely on the basis of clinical requirements, as determined by the team of epileptologists and neurosurgeons (Nourski and Howard, 2015). ECoG data were amplified, filtered (0.7-800 Hz bandpass, $12 \mathrm{~dB} /$ octave rolloff), and digitized at a sampling rate of $2034.5 \mathrm{~Hz}$ using a TDT RZ2 processor (Tucker-Davis Technologies).

Reconstruction of the anatomical locations of implanted electrodes, their mapping onto a standardized set of coordinates, and assignment to ROIs were performed using FreeSurfer image analysis suite (version 5.3; Martinos Center for Biomedical Imaging, Harvard, MA) and in-house software, as described previously (Nourski et al., 2014, 2018). Contact locations of the depth and subdural electrodes were extracted from postimplantation MRI and CT scans, respectively, and projected onto preimplantation MRI scans using nonlinear 3D thin-plate spline morphing. Transformation of recording site locations from multiple subjects into standard MNI coordinates was done using linear coregistration to the MNI152 T1 average brain, as implemented in FMRIB Software library (version 5.0; 
FMRIB Analysis Group, Oxford, UK). Contacts were projected onto the right lateral hemispheric surface and superior temporal plane of the FreeSurfer average template brain. Left hemisphere MNI $x$-axis coordinates $\left(x_{\mathrm{MNI}}\right)$ were multiplied by -1 to map them onto the right hemisphere.

Seven ROIs were defined, spanning the cortical hierarchy of auditory predictive coding: core auditory cortex (posteromedial portion of HG $[\mathrm{HGPM}]$ ); four non-core areas (i.e., anterolateral portion of $\mathrm{HG}$, planum temporale, planum polare, and superior temporal gyrus); auditoryrelated cortex (insular cortex, superior temporal sulcus, middle temporal gyrus [MTG], supramarginal and angular gyri); and PFC (inferior, middle, and superior frontal, orbital, and transverse frontopolar gyrus) (Table 1). Sites outside these seven ROIs were categorized as "Other." Assignment of recording sites to ROIs was based on anatomical reconstructions of electrode locations in each subject, informed by automated parcellation of cortical gyri (Destrieux et al., 2010, 2017) and MRI sections in axial, sagittal, and coronal planes for subdural and depth electrode arrays, respectively. Recording sites characterized by excessive noise, or localized to white matter or seizure foci, were excluded from analyses.

Experimental design and statistical analysis. Stimuli were presented by a TDT RZ2 processor (Tucker-Davis Technologies) and delivered at a comfortable level (60-65 dB SPL) diotically via insert earphones (ER4B, Etymotic Research) integrated into custom-fit earmolds. The target detection task was used to provide additional measures of the subjects' attention and awareness during induction of anesthesia. Subjects operated the button with the hand ipsilateral to the recorded hemisphere. Behavioral performance in the target detection task was characterized by accuracy (hit rate; percentage of detected target stimuli), sensitivity $\left(d^{\prime}\right.$; $Z_{\text {hit rate }}-Z_{\text {false alarm rate, }}$ where $Z(p)$ is the inverse of the cumulative distribution function of the normal distribution), and reaction times (RTs). Button presses had to occur before the onset of the next nontarget trial to be counted as hits.

The first stimulus block was presented immediately before administration of propofol for induction of general anesthesia (Fig. 1D). Following the completion of the first block, propofol was infused at a rate of 50 $\mu \mathrm{g} / \mathrm{kg} / \mathrm{min}$ (Alaris pump, BD Bioscience), and the rate was increased every $10 \mathrm{~min}$ by $25 \mu \mathrm{g} / \mathrm{kg} / \mathrm{min}$ (Nourski et al., 2017). Infusion lasted 50 min, during which three additional LGD blocks were presented. The infusions were supervised by a faculty anesthesiologist using standard respiratory, cardiac, and hemodynamic monitoring. No infusion had to be terminated for the patients' safety.

Depth of anesthesia was evaluated before and after each block using the Observer's Assessment of Alertness/Sedation (OAA/S) scale, a gold standard in assessing alertness in clinical setting (Chernik et al., 1990). Responsiveness (calling the subject's name), speech (asking the subject to repeat the sentence, "The quick brown fox jumps over the lazy dog"), facial expression (the degree of facial relaxation), and eyes (the subject's ability to focus and ptosis) were assessed by the experimenter (K.V.N.) and scored on a scale from 1 to 5 . The composite OAA/S score, ranging from 5 (awake) to 1 (unresponsive), was defined as the lowest level at which any assessment category was checked, as stipulated by Chernik et al. (1990). The transition from OAA/S $=3$ (responsive to loud or repeated command) to OAA/S $=2$ (unresponsive in the absence of mild prodding or shaking) was operationally used as the threshold between sedation and LOC (Vanluchene et al., 2004). Depth of anesthesia was assessed additionally using EEG measures: response entropy (RE; E-ENTROPY module; Datex-Ohmeda) (Viertiö-Oja et al., 2004) in Subject R369 and bispectral index (BIS) (Gan et al., 1997) (BIS Complete 4-Channel Monitor; Medtronic) in all other subjects. The relationship between OAA/S scores and EEG measures was examined using linear regression analysis. BIS/RE values were obtained for each OAA/S measurement by averaging within $\pm 2 \mathrm{~min}$ of that measurement.

ECoG data were downsampled to $1000 \mathrm{~Hz}$ and denoised (Kovach and Gander, 2016). Trials containing voltage deflections $>5$ SD from the across-block mean for each recording site were considered artifacts and excluded from further analysis. Averaged evoked potentials (AEPs) and high gamma event-related band power (ERBP) were extracted using software written in MATLAB (version 7.14; The MathWorks). AEPs and high gamma activity roughly index inputs to and outputs from the cortical recording site, respectively (Steinschneider et al., 2008), thus providing complementary direct measures of neural activity. High gamma ERBP was calculated by bandpass filtering the ECoG signal (300th order finite impulse response filter, $70-150 \mathrm{~Hz}$ passband), followed by Hilbert envelope extraction, log transform, and, for each of the four experimental sequences, normalization to the mean power over the entire duration of the sequence. Averaged AEPs and high gamma ERBP waveforms were smoothed using a fourth-order Butterworth lowpass filter ( $30 \mathrm{~Hz}$ cutoff).

Acoustically responsive sites were identified based on their responses to the first four vowels, as described by Nourski et al. (2014, 2018). Each trial was baseline-corrected by subtracting the mean voltage in the 100 ms interval immediately preceding the onset of the first vowel. Sites were considered responsive if either the upper or the lower bound of the AEP 95\% CI was $<0$ or $>0 \mu \mathrm{V}$, respectively, for at least $30 \mathrm{~ms}$, and the following peak exceeded voltage at the threshold-crossing time point by at least twofold. For high gamma data, the threshold criterion was based on the lower bound of the $95 \% \mathrm{CI}$ exceeding $0 \mathrm{~dB}$ for at least $30 \mathrm{~ms}$, and the following peak exceeding ERBP at the threshold-crossing time point by at least twofold.

LD and GD effects were defined as significant increases in averaged responses to the deviant versus standard stimuli between 0 and $800 \mathrm{~ms}$ following the onset of the fifth vowel, as determined by a nonparametric cluster-based permutation test (Maris and Oostenveld, 2007), as described in detail by Nourski et al. (2018). The permutation distribution was constructed using 10,000 random partitions of experimental conditions (deviant vs standard), and the threshold for the cluster statistic was set at the 99.5th percentile for two-tailed tests (AEP data) and the 99th percentile for the one-tailed tests (high gamma). $p$ values were adjusted using false discovery rate (Benjamini and Hochberg, 1995) correction with a significance threshold of $q=0.05$.

Effects of brain state transitions on responses to the first four vowels, LD effects, and GD effects were analyzed using logistic regression of each response type separately (vowel, LD, GD), with random intercepts for subject, and hierarchical level (core, non-core, auditory-related, PFC) and brain state (awake, sedated, unconscious) as fixed effects with twoway interactions. To facilitate model convergence, normal $(\mathrm{SD}=3)$ priors were used to limit the parameter space ( $\mathrm{R}$ package blme) (Chung et al., 2013). Simultaneous CIs for selected contrasts were calculated with R package multcomp (Hothorn et al., 2008). Data are presented as odds ratios (ORs; i.e., the ratio of the odds of responsiveness in one brain state to the odds in the other brain state, computed by exponentiating the coefficients in the regression analysis) along with 95\% family-wise CIs. All comparisons are across observed brain state transitions (i.e., awake to sedated and sedated to unconscious).

The time course of deviance effects was described by summing significant clusters across recording sites in all subjects for each ROI at each time point between 0 and $800 \mathrm{~ms}$ following the fifth vowel onset. Additionally, cumulative latency probability distribution functions over the same time window were computed for all sites. Time course comparisons between awareness states were performed using two-sample Kolmogorov-Smirnov tests.

\section{Results}

\section{Effects of general anesthesia on behavioral state}

Administration of propofol resulted in decreased OAA/S scores and BIS/RE values (Fig. $2 A$, top row and lower row, respectively) and a decline in button presses (Fig. $2 A$, top row, tick marks). Consistent with previous studies using propofol anesthesia (Liu et al., 1997; Ibrahim et al., 2001), there was a reliable correspondence between OAA/S scores and recorded BIS values (RE in Subject R369) in all subjects (Fig. $2 A$, bottom row, $r^{2}$ values). As expected, subjects exhibited lower accuracy, sensitivity, and longer RTs under sedation (Fig. 2B). 
$\begin{array}{llllll}\text { A } & \text { R369 } & \text { L372 } & \text { R376 } & \text { R394 } & \text { R399 }\end{array}$

OAA/S ( 5 = alert; 1 = deep sleep) and button presses ( $A$ =awake; $S=$ sedated, $U=$ unconscious $)$
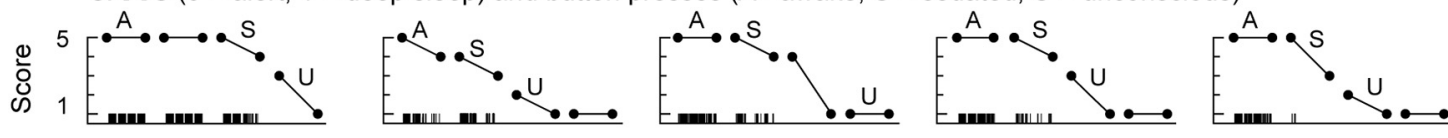

Depth of anesthesia
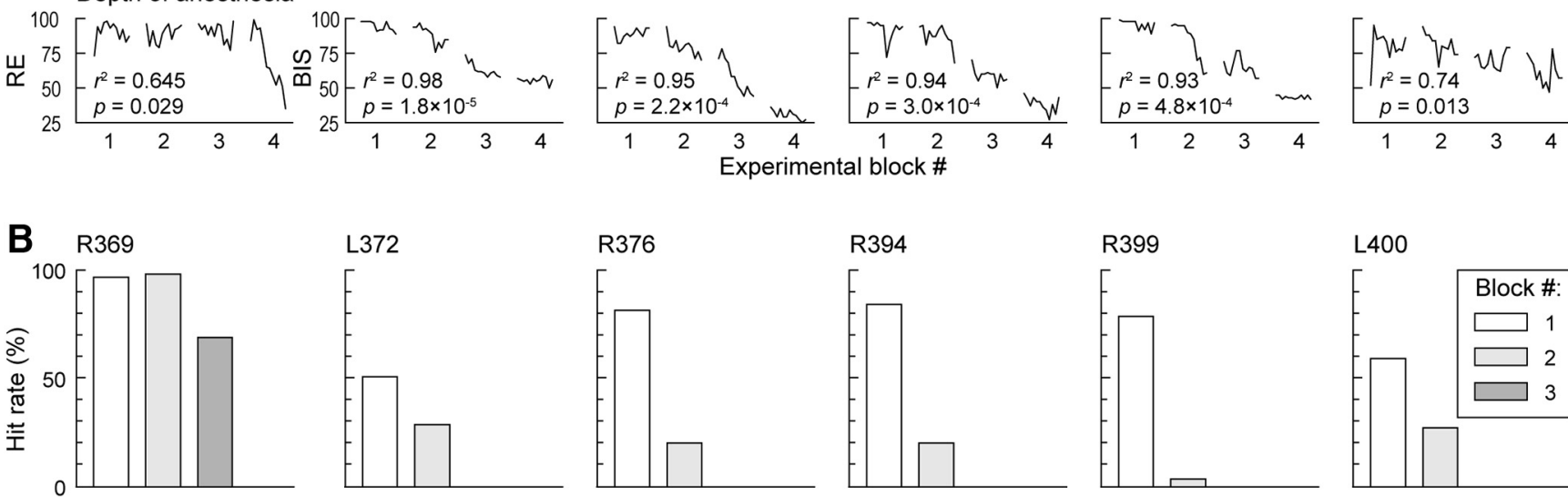

L372
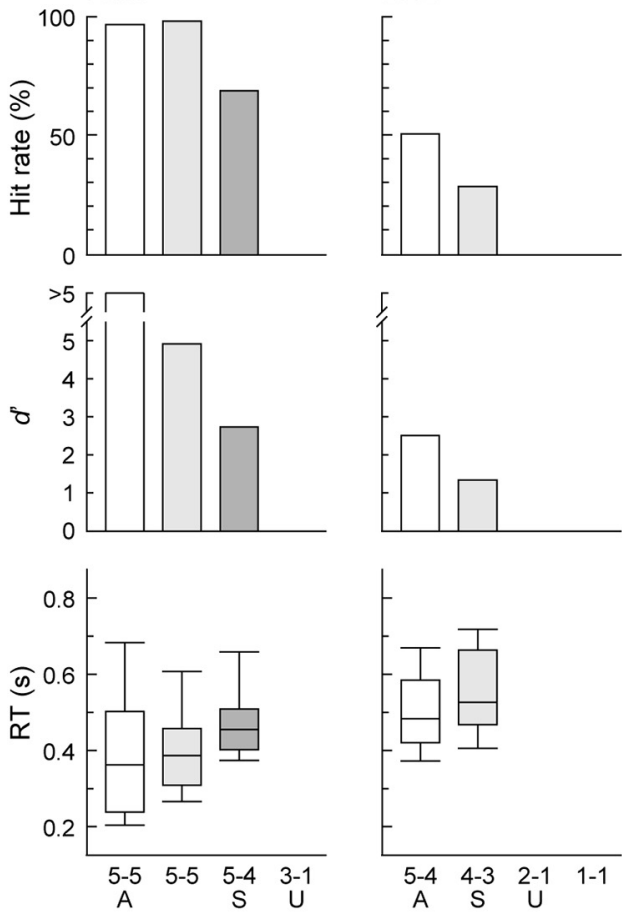
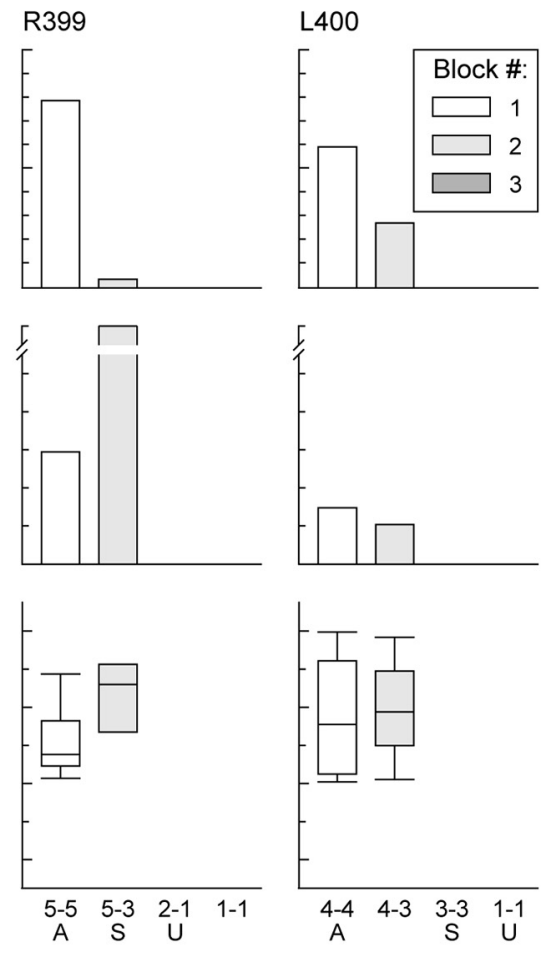

Figure 2. Awareness assessment and GD target detection task performance across experimental blocks. $A$, Assessment of each subject's level of sedation using the $0 A A / S$ scale (top row), and EEG monitoring: RE in Subject R369 and BIS in all other subjects (bottom row) during each experimental block. $B$, Hit rates (percentage correctly detected target stimuli; top), sensitivity ( $d^{\prime}$; middle), and RTs (bottom) for each of the 6 subjects (columns) during the first, second, and third experimental block. None of the subjects pressed the response button during the fourth experimental block. Box-and-whiskers RT plots represent median values and 10th, 25th, 75th, and 90th percentiles; median values for each subject are shown inside boxes. For each block, the two 0AA/S scores correspond to assessments made before and after the LGD experimental block.

\section{Effects of general anesthesia on local versus global novelty responses}

A combination of subdural and depth arrays allowed for comprehensive assessments of responses from multiple ROIs, encompassing key areas in the auditory processing hierarchy. Typical electrode coverage (Subject R369) is presented in Figure 3A. Coverage of the hemispheric convexity by subdural arrays is depicted in the top. A top-down view of the superior temporal plane (Fig. $3 A$, bottom) illustrates placement of depth arrays targeting insular cortex, HG, and the dorsal surface of the anterior temporal lobe. Examples of AEPs and high gamma responses from core auditory cortex (HGPM) and auditory-related cortex (MTG) elicited by LGD stimuli during induction of general anesthesia are shown in Figure $3 B$. Auditory novelty, associated with the onset of the fifth vowel within the stimulus, elicited deviance effects in AEP and high gamma ERBP signals. Both AEP and high gamma LD effects were preserved within HGPM throughout in- duction. In MTG, an AEP LD effect was present under sedation, but not LOC. In contrast, significant GD effects were abolished under sedation at both sites.

Details of LGD effects associated with induction of general anesthesia are presented in Figure 4, which depicts data from all subjects plotted in the MNI coordinate space for the three levels of awareness. In the awake state, AEP LD effects were present in all ROIs, whereas high gamma LD effects were absent in PFC (Fig. $4 A$ ). Both AEP and high gamma LD effects became progressively restricted to core and non-core auditory cortex under propofol anesthesia. Of note, there was little change in extent of LD effects in temporoparietal cortex from awake to sedated state.

AEP and high gamma GD effects were observed in all ROIs in the awake state (Fig. 4B). GD effects were more sensitive to propofol compared with LD effects and were largely suppressed in all areas under sedation. Of note, the majority of remaining sites with significant AEP (19 of 25) and high gamma (20 of 29) 

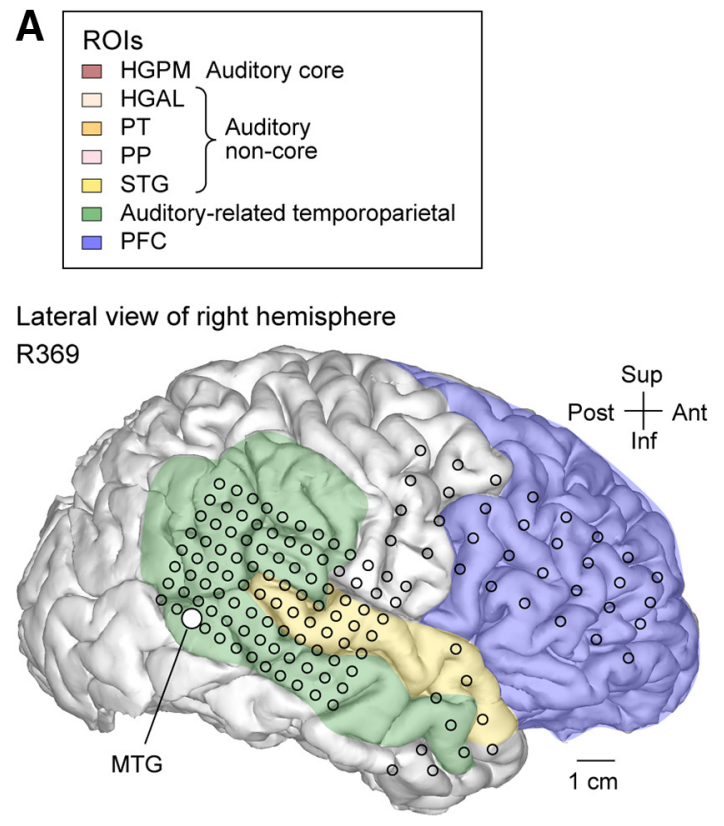

Top-down view of right superior temporal plane

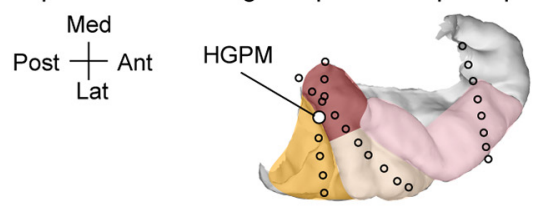

B
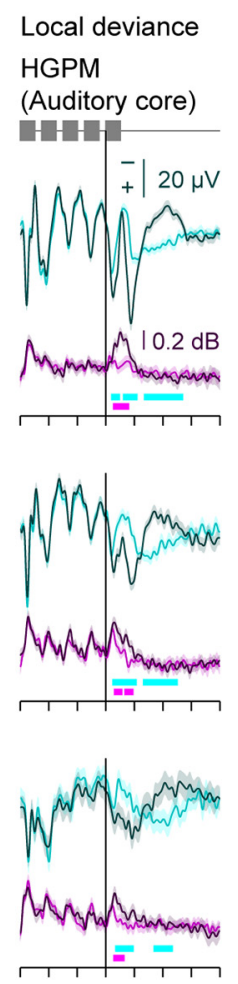

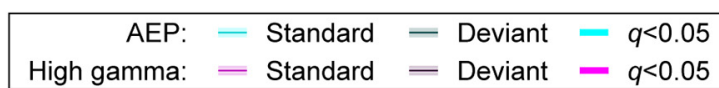

Global deviance

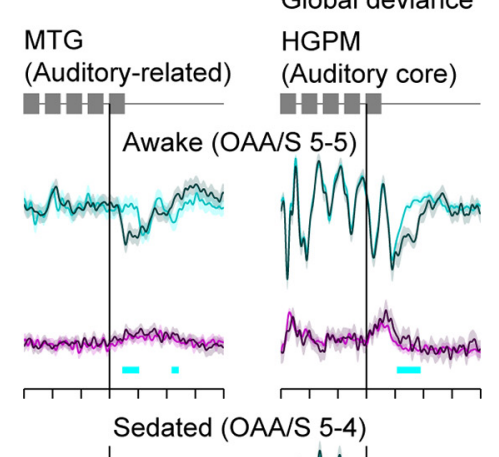

MTG

(Auditory-related)
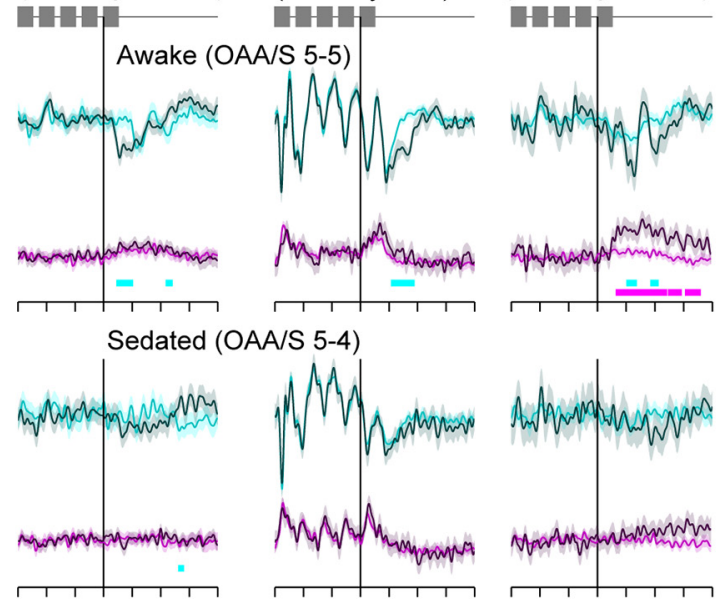

OAA/S 3-1)
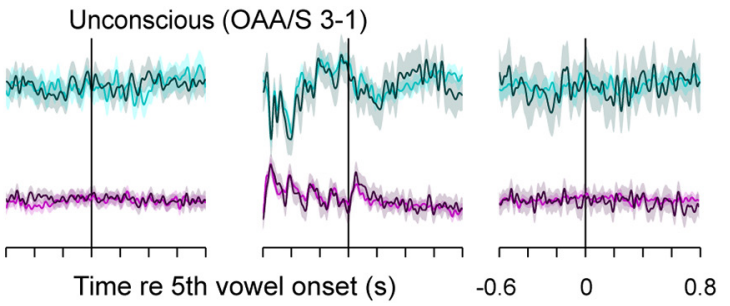

Figure 3. Responses to standard and deviant stimuli during induction of general anesthesia in a representative subject (Subject R369). $\boldsymbol{A}$, MRI side view of the hemispheric surface and top-down view of superior temporal plane showing electrode coverage in Subject R369. Circles represent recording sites. White circles represent recording sites in HGPM and MTG. Colors represent different ROls used in the study. B, AEP and high gamma responses recorded from two exemplary sites in response to standard and deviant stimuli. Lines indicate mean values. Shading represents $95 \%$ Cls. Thick lines underneath response waveforms indicate significant differences between responses to standard and deviant stimuli.

GD effects under sedation were contributed by a single subject (Subject R376). This participant was otherwise typical of the subject cohort, including task performance, extent of electrode coverage, and changes in LD effects during induction.

The description of regional changes in LGD effects during induction of propofol anesthesia shown in Figure 4 could be biased by the extent of ROI electrode coverage. To address this, and to compare changes in LGD effects with changes in overall responsiveness to acoustic stimuli, the presence of responses to vowels and LGD effects across cortical regions was also described in terms of the fractions of responsive sites (Fig. 5), and the effects of changes in brain state on responsiveness analyzed using logistic regression (see Materials and Methods). No significant effect of brain state was detected on AEP vowel responses in core $(\mathrm{OR}=$ $0.28[0.0096,8.0], p=0.94)$. In non-core, there was no effect of sedation $(\mathrm{OR}=0.79[0.33,1.9], p=0.99)$, but responses were suppressed upon LOC $(\mathrm{OR}=0.38[0.18,0.80], p=0.0034)$. Responses were suppressed upon both sedation and LOC in auditory-related cortex (sedation: $\mathrm{OR}=0.57[0.35,0.94], p=$ 0.017 ; LOC: $\mathrm{OR}=0.26[0.14,0.48], p<0.001)$ and PFC (sedation: $\mathrm{OR}=0.20[0.092,0.42], p<0.001$; LOC: $\mathrm{OR}=0.16[0.034$, 0.72 ], $p=0.0074$ ) (Fig. $5 A$ ). No effect on high gamma responses to vowels was detected for any hierarchical level and brain state ( $p>0.05$ for all contrasts).

Analysis of LGD effects (Fig. $5 B, C$ ) yielded results consistent with those presented in Figure 4 . Specifically, there was no significant difference in AEP and high gamma LD effects between awake and sedated states $(p>0.05$ for all contrasts), except for AEP LD effects in PFC, which were suppressed $(\mathrm{OR}=0.21[0.010,0.45], p<0.001)$ (Fig. 5B). In comparison, LD effects were suppressed outside of auditory core cortex upon LOC ( $p<0.05$ for all contrasts). AEP GD effects were suppressed at all levels of hierarchy in sedation $(p<0.05$ for all contrasts). Statistical assessment of state-dependent changes of AEP GD effects upon LOC and high gamma GD effects upon sedation and LOC was precluded by the small number of responsive sites (Fig. $5 C$ ).

Sensitivity of FB pathways and higher-order cortical areas to general anesthesia would be expected to alter the time course of cortical activation associated with predictive coding. To address this, the overall time course of LGD effects was measured across all ROIs (Fig. 6). Here, at each time point relative to the onset of the fifth vowel, numbers of ROI sites exhibiting significant differences between responses to standard and deviant stimuli were summed across subjects, demonstrating the extent of cortical activation by auditory novelty on a temporal scale. In the awake state, AEP LD and GD effects exhibited multipeaked time courses that spanned the entire $800 \mathrm{~ms}$ analysis window, whereas high gamma effects were largely monophasic and occurred earlier in the analysis window (Fig. 6A). The AEP LD effect was most prominent at $150-250 \mathrm{~ms}$ after the fifth vowel onset, whereas the high gamma LD effect peaked at $\sim 125 \mathrm{~ms}$. The time courses of AEP and high gamma LD effects were slower under sedation relative to awake (AEP: $D=0.093, p<0.001$; high gamma: $D=$ $0.22, p<0.001$; two-sample Kolmogorov-Smirnov tests) (Fig. $6 A$, insets). Upon LOC, the AEP LD effect had a more rapid time 


\section{A Local deviance effect}
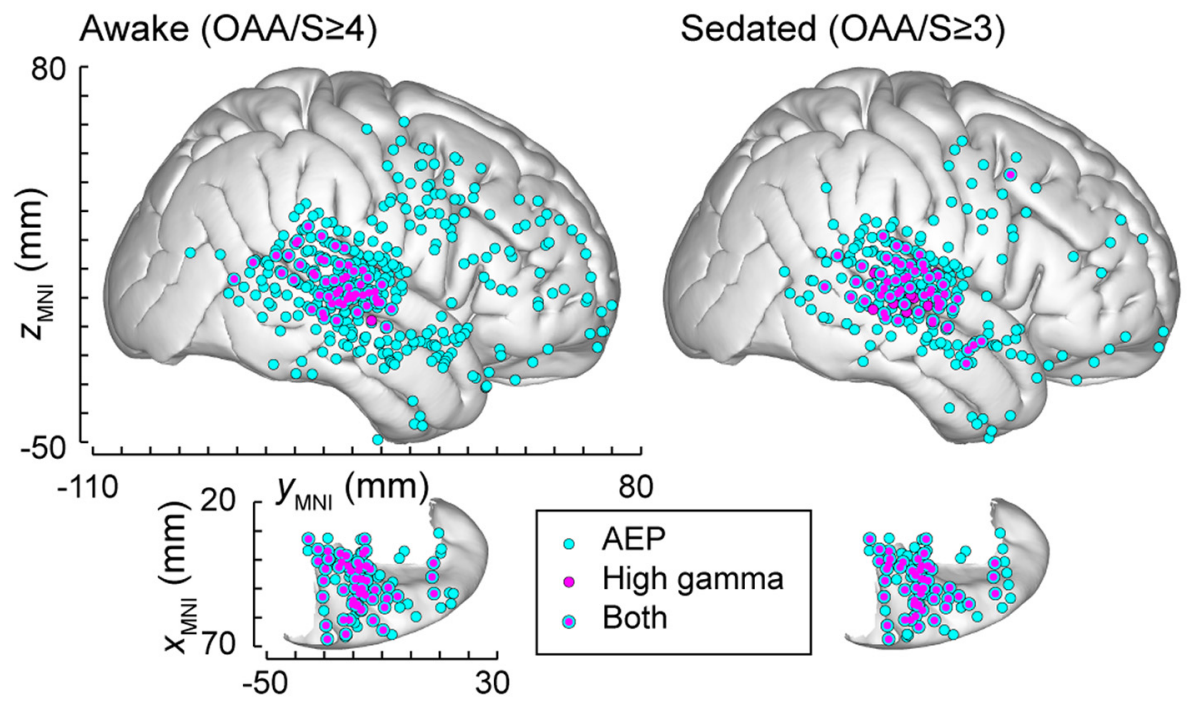

\section{B Global deviance effect Awake $(\mathrm{OAA} / \mathrm{S} \geq 4)$}

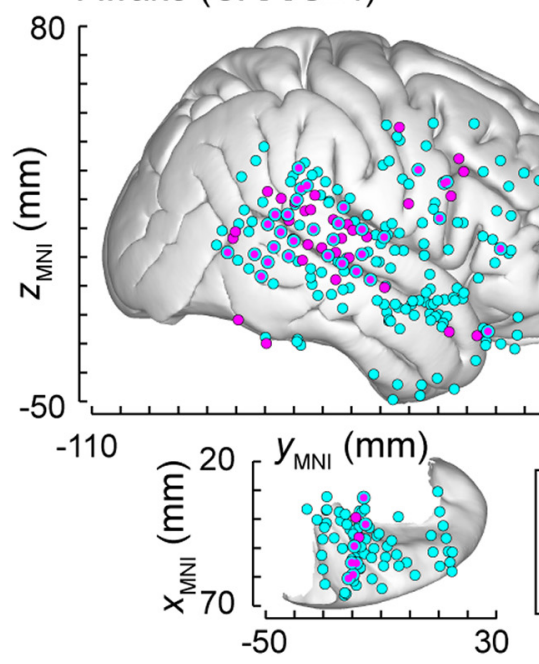

\section{Unconscious $(\mathrm{OAA} / \mathrm{S}<3)$}
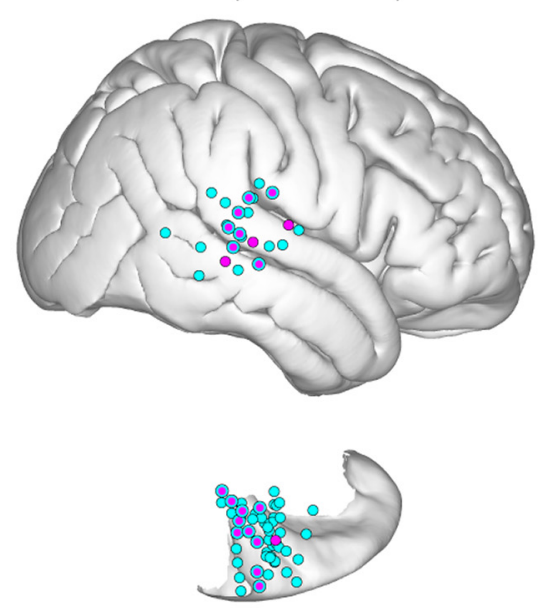

\section{Unconscious (OAA/S $<3)$}
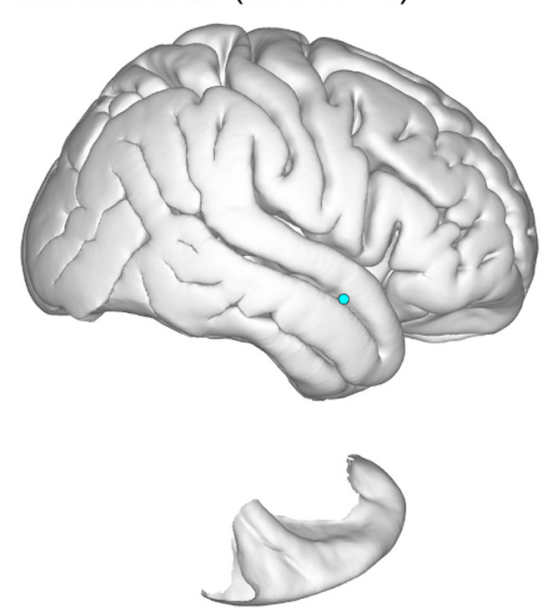

Figure 4. Topography of changes in $L D(A)$ and GD $(B)$ effects during induction of general anesthesia. Summary of data from 6 subjects, plotted in MNI coordinate space and projected onto FreeSurfer average template brain. Left hemisphere MNI $x$-axis coordinates $\left(x_{M N}\right)$ were multiplied by -1 to map them onto the right-hemisphere common space.

course compared with te sedated state $(D=0.086, p<0.001)$, reflecting the relatively higher contribution of HGPM sites. A similar effect was observed for high gamma, where the timing of LD effects was more rapid upon LOC compared with sedation $(D=0.25, p<0.001)$.

As expected, onset and peak latencies of GD effects were generally longer than those of LD effects. The number of sites exhibiting significant AEP GD effects was maximal at $\sim 400 \mathrm{~ms}$, whereas the high gamma GD effect peaked at $250 \mathrm{~ms}$. The time course of GD effects became less complex in the sedated compared with the awake state. For AEP, this was associated with selective loss of the earliest components $(D=0.18, p<0.001)$, whereas for high gamma later components were suppressed under sedation $(D=0.28, p<0.001)$. Of note, as GD effects were profoundly suppressed under sedation and abolished upon LOC, these results were based on a small number of significant sites, primarily from a single subject, and should be interpreted with caution.
Relationship between LGD responses and task performance

The physiologic data indicate that loss of GD effects does not index LOC, and instead may reflect changes in the subjects' task engagement. To that end, relationships between cortical LGD responses and task performance before and during induction of general anesthesia were examined using linear regression analysis. Behavioral accuracy (hit rate) while subjects were engaged in the task (i.e., blocks with hit rates $>0 \%$ ) was compared with the percentages of sites in superior temporal gyrus (STG), auditoryrelated cortex, and PFC that exhibited AEP LGD effects in corresponding experimental blocks. This relationship failed to reach significance for LD AEP effect in all three regions (STG: $r^{2}=$ $0.058 ; p=0.48$; auditory-related cortex: $r^{2}=0.0041 ; p=0.84$; PFC: $\left.r^{2}=0.0080 ; p=0.77\right)$. Likewise, the linear correlation between the prevalence of AEP GD effect in STG and task performance failed to reach significance $\left(r^{2}=0.23 ; p=0.13\right)$. In contrast, there was a trend toward significance for correlation between AEP GD effects and accuracy in auditory-related cortex 
A Responses to the first four vowels

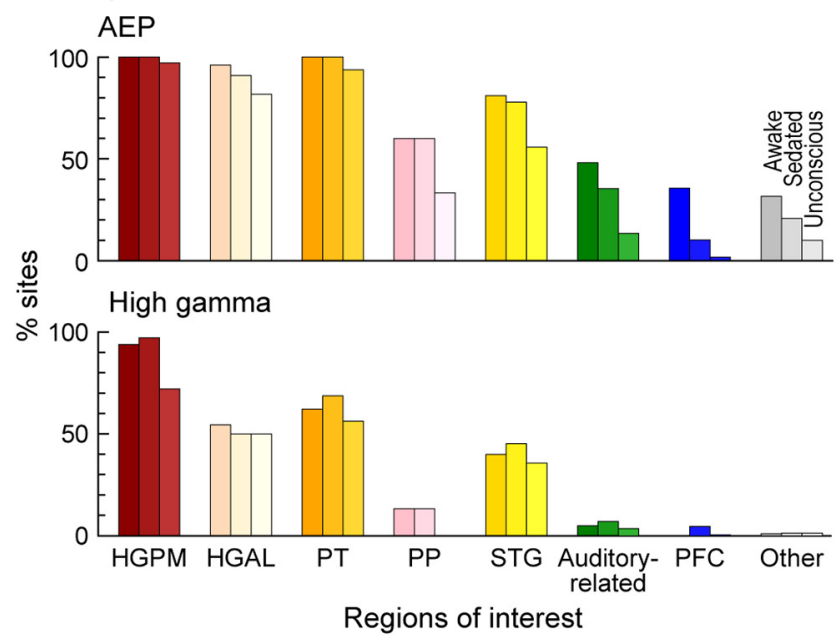

B Local deviance effect

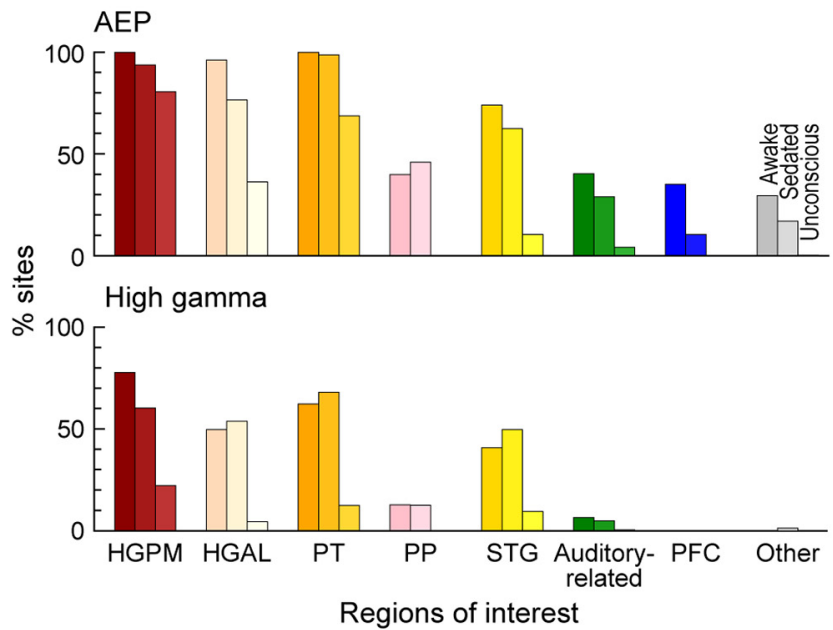

C Global deviance effect

AEP
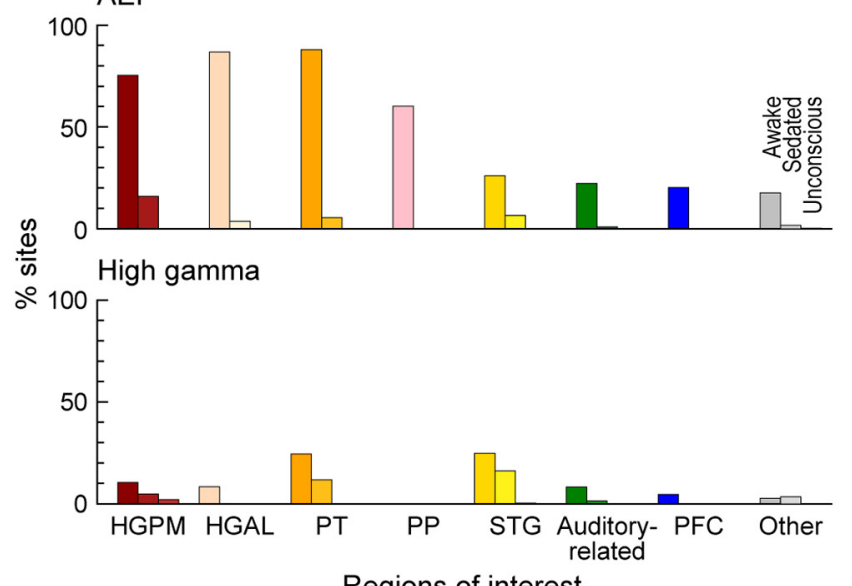

Regions of interest

Figure 5. Percentages of sites across ROls that exhibited responses to the first four vowels, LD effects, and GD effects ( $\boldsymbol{A}-\boldsymbol{C}$, respectively). Summary of data from 6 subjects. Differently shaded bars represent measurements made in awake, sedated, and unconscious states. $\left(r^{2}=0.32 ; p=0.043\right.$, uncorrected $)$ and PFC $\left(r^{2}=0.42 ; p=\right.$ 0.016 , uncorrected). This result is consistent with the model wherein GD effects in auditory-related cortex and PFC index the subject's task performance rather than consciousness per se.

\section{Discussion}

Sensitivity of novelty responses to anesthesia

Electrophysiological studies have shown that fundamental aspects of auditory responses in core auditory cortex are relatively robust to LOC under anesthesia (Raz et al., 2014; Durand et al., 2016; Nourski et al., 2017), whereas responses in higher-order areas, including association sensory cortex and PFC, are far more sensitive (Heinke et al., 2004; Plourde et al., 2006; Liu et al., 2012; Nourski et al., 2017). In the present study, modulation of LD effects by propofol exhibited a similar spatial distribution. LD effects remain present in core and non-core auditory cortex, even upon LOC. This observation is similar to that seen in animal models, wherein the modulatory effects of preceding stimuli upon a test sound are present even in the anesthetized state (Calford and Semple, 1995). In contrast, LD effects outside auditory cortex are strongly affected by general anesthesia, indicative of a progressive suppression of downstream nodes within the network that subserves predictive coding at the LD time scale.

The LGD stimulation paradigm simultaneously probes conscious and unconscious processing of novelty within the predictive coding framework. Several studies have provided evidence that, unlike LD effects, which were resistant to LOC, GD effects had the potential to serve as biomarkers for conscious sensory processing. This proposition was based on comparisons between controls and patients with DOC (Bekinschtein et al., 2009; Faugeras et al., 2012), during sleep (Strauss et al., 2015), and, in monkeys, under general anesthesia (Uhrig et al., 2016). The differential sensitivity of the LD and GD effects to behavioral state is consistent with the initial assumption upon which the LGD paradigm was based (i.e., that "maintenance of perceptual representations over time requires consciousness") (Bekinschtein et al., 2009). However, the data presented here are inconsistent with the proposal that loss of GD effects tracks LOC. In the current study, GD effects were almost entirely suppressed at sedating doses of propofol, even while subjects were still responsive. Results are also inconsistent with an earlier fMRI study in monkeys (Uhrig et al., 2016), which reported a complete suppression of the LD effect by propofol, accompanied by only partial suppression of the GD effect, essentially the opposite to the differential sensitivity demonstrated here. It is possible this discrepancy reflects species-or task-specific effects, or differences in methodology or experimental design.

Although the MMN is classically described as preattentive and thus resistant to LOC (Näätänen et al., 2011), the present study shows that LD effects in PFC are blocked by propofol under sedation. This sensitivity to propofol anesthesia is consistent with previous reports showing that the amplitude of the LD effect and the MMN are sensitive to manipulations of attention (Näätänen et al., 1993; Chennu et al., 2013) and to changes in levels of consciousness (Simpson et al., 2002; Strauss et al., 2015; Uhrig et al., 2016). These reports, as well as the present findings, suggest that the generators of the LD effect and the MMN are multifactorial, with preattentive processing localized to auditory cortex and additional contributions localized to higher-order regions. The latter contributions manifest over longer time scales, likely reflecting a greater degree of polysynaptic processing across brain regions, which in turn would lead to greater susceptibility to disruption by general anesthesia (Hentschke et al., 2017). Con- 


\section{A Local deviance effect}

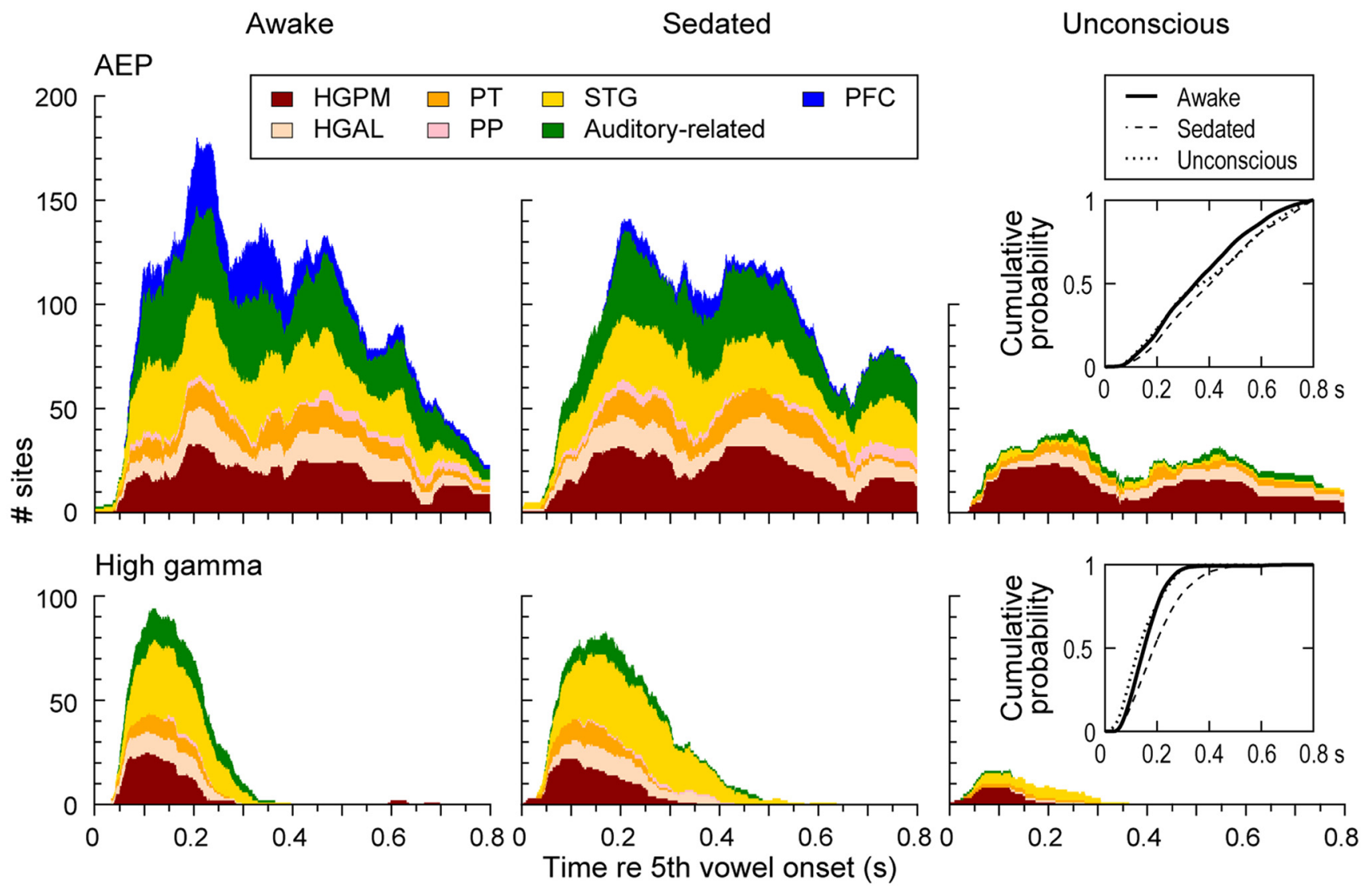

\section{B Global deviance effect}

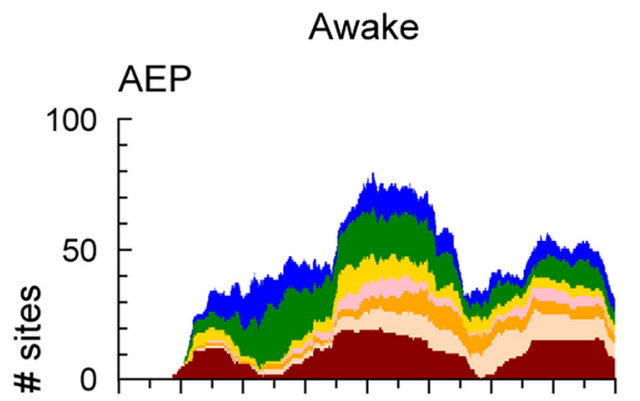

\section{Sedated}
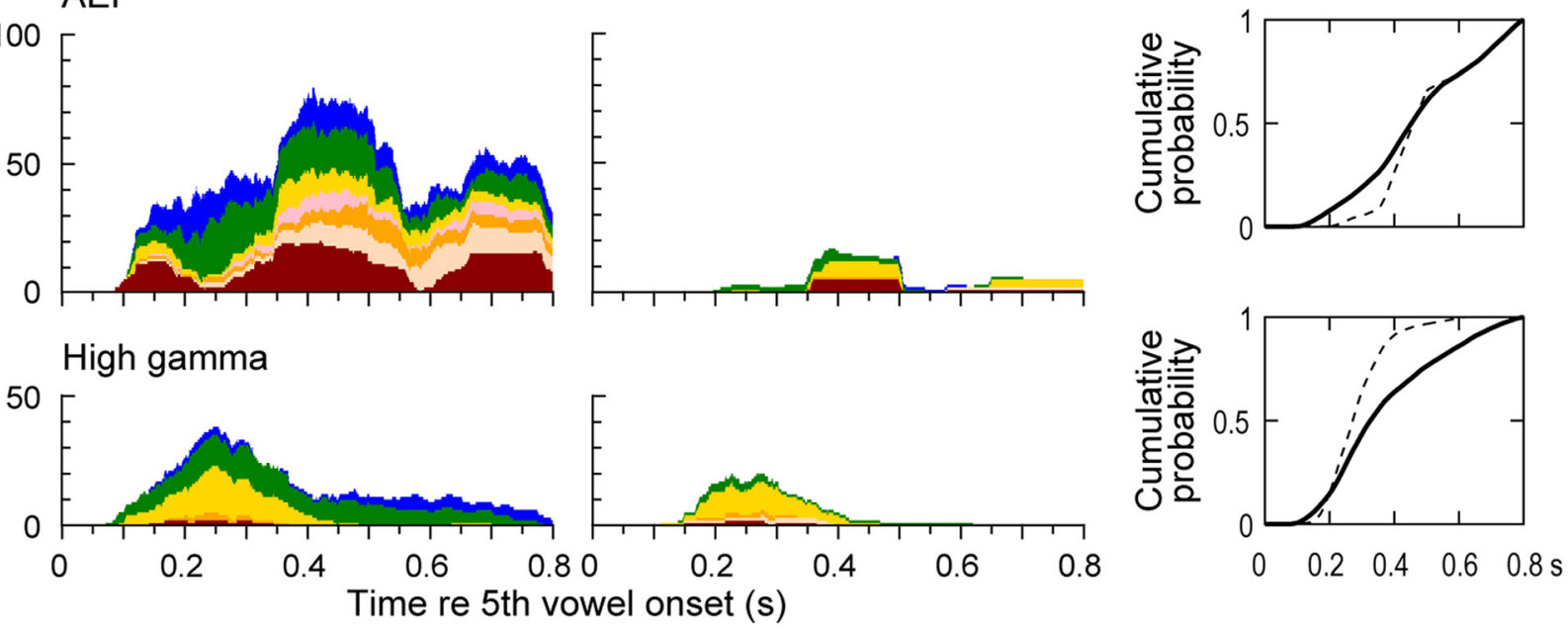

Figure 6. Time course of $L D(A)$ and GD $(\boldsymbol{B})$ effects across levels of awareness (columns). Data from 6 subjects. Number of sites within each R0I, exhibiting significant differences between responses to standard and deviant stimuli, are plotted as a function of time after the fifth vowel onset for AEP and high gamma in top and bottom rows, respectively. Insets, Cumulative probability distribution plots comparing the overall time course of deviance effects for all recording sites. Solid line indicates awake. Dashed line indicates sedated. Dotted line indicates unconscious. No data are shown for GD effects upon $\mathrm{LOC}$ due to the lack of responsive sites.

sistent with this model, the overall time course of LD effects was truncated upon LOC compared with sedation. Finally, the STG was characterized by some of the most dramatic reductions in LD effects upon LOC in the present study. This suggests that the STG may be a critical hub for initiation of conscious processing of deviance effects.

The AEP GD effect reported in the present study had timing and, in part, spatial distribution comparable with that of the 
scalp-recorded P300 response. Of note, other studies have specifically linked GD effects to the P3b component of that response (e.g., Bekinschtein et al., 2009). The attenuation of the GD effect and $\mathrm{P} 3 \mathrm{~b}$ in normal sleeping subjects and DOC patients, and under anesthesia in the monkey, has been interpreted as an indication that GD effects require conscious processing of sensory information (Bekinschtein et al., 2009; Faugeras et al., 2012; Strauss et al., 2015). Given the dependence of these relatively long-latency deviance effects on attention and working memory (Sergent et al., 2005; Bekinschtein et al., 2009; Chennu et al., 2013), this sensitivity to level of consciousness is not surprising. Indeed, current models of loss and recovery of consciousness, both under anesthesia and during natural sleep, emphasize the importance of anesthetic-induced changes in cortical connectivity, and especially FB connectivity (Mashour and Hudetz, 2017). Deviance detection, and especially GD, is postulated to depend on FB projections within the cortical hierarchy underlying auditory predictive coding (Bekinschtein et al., 2009). Thus, its sensitivity to anesthesia is consistent with the sensitivity of FB projections to anesthesia. However, does GD detection reflect consciousness per se, or merely some of its attentional or cognitive components? Loss of GD effects at subhypnotic doses of propofol (Fig. 4) suggests the latter, leading to the conclusion that these cortical responses are not a reliable measure of consciousness. The sensitivity of GD effects to manipulations of attention and the overlap of the areas contributing to GD effects and attention (Hopfinger et al., 2000; Corbetta and Shulman, 2002) suggest that GD effects may be more directly related to attention, which is impaired even under subhypnotic doses of anesthesia (Heinke and Koelsch, 2005), and is absent during all stages of natural sleep and in most DOC patients (Bekinschtein et al., 2009; Faugeras et al., 2012; Strauss et al., 2015).

\section{Caveats and limitations}

The experimental subjects in this study had a neurologic disorder and thus may not be representative of a healthy population. However, results were consistent across multiple subjects with different neurologic histories, antiepileptic drug regimens, and seizure foci. All subjects had normal cognitive function and were able to perform the experimental task successfully. Further, recordings from epileptic foci in each subject were excluded from the analyses. Importantly, over the course of the monitoring period, all subjects participated in multiple experimental protocols beyond those described in the present report. These multiple paradigms provide for a comprehensive assessment of cortical function, and evaluation for consistency with a corpus of published data on basic electrophysiologic response properties (Nourski and Howard, 2015; Nourski, 2017). None of the subjects exhibited aberrant behavioral or physiologic responses during performance of these other protocols that would serve as grounds for exclusion from the present study.

It is challenging to clinically assess level of consciousness in human subjects (Sanders et al., 2012; Bayne et al., 2017; Bernat, 2017). Here, responsiveness to verbal command, evaluated by the $\mathrm{OAA} / \mathrm{S}$ score, was used as a surrogate measure. However, loss of responsiveness could reflect lack of motivation to respond despite continued sensory processing, or could reflect disconnection from the environment accompanied by dreaming, which is reported to occur under propofol anesthesia (Leslie et al., 2009). Without a direct assay of mentation available, responsiveness and/or recall are the current gold standards for assessing consciousness in patients and volunteers being administered anesthesia, and are highly correlated with assays of LOC in animal models (Franks, 2008). In the future, converging lines of evidence based on studies in humans, animal studies establishing underlying mechanisms (Funk et al., 2017), and theoretical and computational models of consciousness (Dehaene and Changeux, 2011; Tononi et al., 2016) will provide a firmer foundation for interrogating consciousness in human subjects.

\section{Functional significance and future directions}

Research into the neural basis of consciousness has converged with research examining mechanisms of anesthesia, sleep, and DOC (Mashour, 2006; Alkire et al., 2008; Shushruth, 2013). Establishing neural signatures of altered consciousness and LOC will prove invaluable for advancing these fields of study, and will also have practical applications related to noninvasive monitors of awareness and diagnostic and prognostic tools for use in patients with DOC and mental illness. Clinical evaluation alone lacks sensitivity and specificity, and adjunct objective measures that can reliably index the absence of consciousness would enhance the nosology of DOC (Bayne et al., 2017; Bernat, 2017). The data presented here suggest that auditory novelty responses may be useful in developing such metrics, but it is critical to consider both the specific cortical generators that contribute to the novelty response and the role of other factors (e.g., subjects' motivation and attention during task performance) in mediating activation of the brain regions involved. Future studies that more strictly control for possible task-related effects are imperative for resolving the latter issue, and development of stimulus paradigms independent of active participation of the patient is of translational importance.

\section{References}

Alkire MT, Hudetz AG, Tononi G (2008) Consciousness and anesthesia. Science 322:876-880. CrossRef Medline

Avidan MS, Jacobsohn E, Glick D, Burnside BA, Zhang L, Villafranca A, Karl L, Kamal S, Torres B, O'Connor M, Evers AS, Gradwohl S, Lin N, Palanca BJ, Mashour GA (2011) Prevention of intraoperative awareness in a high-risk surgical population. N Engl J Med 365:591-600. CrossRef Medline

Bar M (2009) The proactive brain: memory for predictions. Philos Trans R Soc Lond B Biol Sci 364:1235-1243. CrossRef Medline

Bastos AM, Usrey WM, Adams RA, Mangun GR, Fries P, Friston KJ (2012) Canonical microcircuits for predictive coding. Neuron 76:695-711. CrossRef Medline

Bayne T, Hohwy J, Owen AM (2017) Reforming the taxonomy in disorders of consciousness. Ann Neurol 82:866-872. CrossRef Medline

Bekinschtein TA, Dehaene S, Rohaut B, Tadel F, Cohen L, Naccache L (2009) Neural signature of the conscious processing of auditory regularities. Proc Natl Acad Sci U S A 106:1672-1677. CrossRef Medline

Benjamini Y, Hochberg Y (1995) Controlling the false discovery rate: a practical and powerful approach to multiple testing. J R Stat Soc B Stat Methodol 57:289-300.

Bernat JL (2017) Nosologic considerations in disorders of consciousness. Ann Neurol 82:863-865. CrossRef Medline

Boly M, Moran R, Murphy M, Boveroux P, Bruno MA, Noirhomme Q, Ledoux D, Bonhomme V, Brichant JF, Tononi G, Laureys S, Friston K (2012) Connectivity changes underlying spectral EEG changes during propofol-induced loss of consciousness. J Neurosci 32:7082-7090. CrossRef Medline

Calford MB, Semple MN (1995) Monaural inhibition in cat auditory cortex. J Neurophysiol 73:1876-1891. CrossRef Medline

Chennu S, Noreika V, Gueorguiev D, Blenkmann A, Kochen S, Ibáñez A, Owen AM, Bekinschtein TA (2013) Expectation and attention in hierarchical auditory prediction. J Neurosci 33:11194-11205. CrossRef Medline

Chernik DA, Gillings D, Laine H, Hendler J, Silver JM, Davidson AB, Schwam EM, Siegel JL (1990) Validity and reliability of the Observer's assessment of Alertness/Sedation scale: study with intravenous midazolam. J Clin Psychopharmacol 10:244-251. Medline 
Chung Y, Rabe-Hesketh S, Dorie V, Gelman A, Liu J (2013) A nondegenerate penalized likelihood estimator for variance parameters in multilevel models. Psychometrika 78:685-709. CrossRef Medline

Clark A (2013) Whatever next? Predictive brains, situated agents, and the future of cognitive science. Behav Brain Sci 36:181-204. CrossRef Medline

Corbetta M, Shulman GL (2002) Control of goal-directed and stimulusdriven attention in the brain. Nat Rev Neurosci 3:201-215. CrossRef Medline

Crick F, Koch C (2003) A framework for consciousness. Nat Neurosci 6:119-126. CrossRef Medline

Davis MH, Johnsrude IS (2007) Hearing speech sounds: top-down influences on the interface between audition and speech perception. Hear Res 229:132-147. CrossRef Medline

Dehaene S, Changeux JP (2011) Experimental and theoretical approaches to conscious processing. Neuron 70:200-227. CrossRef Medline

Dehaene S, Naccache L (2001) Towards a cognitive neuroscience of consciousness: basic evidence and a workspace framework. Cognition 79:137. CrossRef Medline

Destrieux C, Fischl B, Dale A, Halgren E (2010) Automatic parcellation of human cortical gyri and sulci using standard anatomical nomenclature. Neuroimage 53:1-15. CrossRef Medline

Destrieux C, Terrier LM, Andersson F, Love SA, Cottier JP, Duvernoy H, Velut S, Janot K, Zemmoura I (2017) A practical guide for the identification of major sulcogyral structures of the human cortex. Brain Struct Funct 222:2001-2015. CrossRef Medline

Devor M, Zalkind V (2001) Reversible analgesia, atonia, and loss of consciousness on bilateral intracerebral microinjection of pentobarbital. Pain 94:101-112. CrossRef Medline

Durand S, Iyer R, Mizuseki K, de Vries S, Mihalas S, Reid RC (2016) A comparison of visual response properties in the lateral geniculate nucleus and primary visual cortex of awake and anesthetized mice. J Neurosci 36:12144-12156. CrossRef Medline

Faugeras F, Rohaut B, Weiss N, Bekinschtein T, Galanaud D, Puybasset L, Bolgert F, Sergent C, Cohen L, Dehaene S, Naccache L (2012) Event related potentials elicited by violations of auditory regularities in patients with impaired consciousness. Neuropsychologia 50:403-418. CrossRef Medline

Ferrarelli F, Massimini M, Sarasso S, Casali A, Riedner BA, Angelini G, Tononi G, Pearce RA (2010) Breakdown in cortical effective connectivity during midazolam-induced loss of consciousness. Proc Natl Acad Sci U S A 107:2681-2686. CrossRef Medline

Fishman YI (2014) The mechanisms and meaning of the mismatch negativity. Brain Topogr 27:500-526. CrossRef Medline

Franks NP (2008) General anaesthesia: from molecular targets to neuronal pathways of sleep and arousal. Nat Rev Neurosci 9:370-386. CrossRef Medline

Friston K (2005) A theory of cortical responses. Philos Trans R Soc Lond B Biol Sci 360:815-836. CrossRef Medline

Funk CM, Peelman K, Bellesi M, Marshall W, Cirelli C, Tononi G (2017) Role of somatostatin-positive cortical interneurons in the generation of sleep slow waves. J Neurosci 37:9132-9148. CrossRef Medline

Gan TJ, Glass PS, Windsor A, Payne F, Rosow C, Sebel P, Manberg P (1997) Bispectral index monitoring allows faster emergence and improved recovery from propofol, alfentanil, and nitrous oxide anesthesia. BIS utility study group. Anesthesiology 87:808-815. CrossRef Medline

Garrido MI, Kilner JM, Stephan KE, Friston KJ (2009) The mismatch negativity: a review of underlying mechanisms. Clin Neurophysiol 120:453463. CrossRef Medline

Heinke W, Koelsch S (2005) The effects of anesthetics on brain activity and cognitive function. Curr Opin Anaesthesiol 18:625-631. CrossRef Medline

Heinke W, Fiebach CJ, Schwarzbauer C, Meyer M, Olthoff D, Alter K (2004) Sequential effects of propofol on functional brain activation induced by auditory language processing: an event-related functional magnetic resonance imaging study. Br J Anaesth 92:641-650. CrossRef Medline

Hentschke H, Raz A, Krause BM, Murphy CA, Banks MI (2017) Disruption of cortical network activity by the general anesthetic isoflurane. Br J Anaesth 119:685-696. CrossRef Medline

Hillenbrand J, Getty LA, Clark MJ, Wheeler K (1995) Acoustic characteristics of American English vowels. J Acoust Soc Am 97:3099-3111. CrossRef Medline

Hopfinger JB, Buonocore MH, Mangun GR (2000) The neural mechanisms of top-down attentional control. Nat Neurosci 3:284-291. CrossRef Medline

Hothorn T, Bretz F, Westfall P (2008) Simultaneous inference in general parametric models. Biom J 50:346-363. CrossRef Medline

Ibrahim AE, Taraday JK, Kharasch ED (2001) Bispectral index monitoring during sedation with sevoflurane, midazolam, and propofol. Anesthesiology 95:1151-1159. CrossRef Medline

Joos K, Gilles A, Van de Heyning P, De Ridder D, Vanneste S (2014) From sensation to percept: the neural signature of auditory event-related potentials. Neurosci Biobehav Rev 42:148-156. CrossRef Medline

Koch C, Massimini M, Boly M, Tononi G (2016) Neural correlates of consciousness: progress and problems. Nat Rev Neurosci 17:307-321. CrossRef Medline

Kok A (2001) On the utility of P3 amplitude as a measure of processing capacity. Psychophysiology 38:557-577. CrossRef Medline

Kovach CK, Gander PE (2016) The demodulated band transform. J Neurosci Methods 261:135-154. CrossRef Medline

Långsjö JW, Alkire MT, Kaskinoro K, Hayama H, Maksimow A, Kaisti KK, Aalto S, Aantaa R, Jääskeläinen SK, Revonsuo A, Scheinin H (2012) Returning from oblivion: imaging the neural core of consciousness. J Neurosci 32:4935-4943. CrossRef Medline

Leslie K, Sleigh J, Paech MJ, Voss L, Lim CW, Sleigh C (2009) Dreaming and electroencephalographic changes during anesthesia maintained with propofol or desflurane. Anesthesiology 111:547-555. CrossRef Medline

Liu J, Singh H, White PF (1997) Electroencephalographic bispectral index correlates with intraoperative recall and depth of propofol-induced sedation. Anesth Analg 84:185-189. CrossRef Medline

Liu X, Lauer KK, Ward BD, Rao SM, Li SJ, Hudetz AG (2012) Propofol disrupts functional interactions between sensory and high-order processing of auditory verbal memory. Hum Brain Mapp 33:2487-2498. CrossRef Medline

Llinás R, Ribary U, Contreras D, Pedroarena C (1998) The neuronal basis for consciousness. Philos Trans R Soc Lond B Biol Sci 353:1841-1849. CrossRef Medline

Maris E, Oostenveld R (2007) Nonparametric statistical testing of EEG- and MEG-data. J Neurosci Methods 164:177-190. CrossRef Medline

Mashour GA (2006) Integrating the science of consciousness and anesthesia. Anesth Analg 103:975-982. CrossRef Medline

Mashour GA (2013) Cognitive unbinding: a neuroscientific paradigm of general anesthesia and related states of unconsciousness. Neurosci Biobehav Rev 37:2751-2759. CrossRef Medline

Mashour GA, Hudetz AG (2017) Bottom-up and top-down mechanisms of general anesthetics modulate different dimensions of consciousness. Front Neural Circuits 11:44. CrossRef Medline

Massimini M, Ferrarelli F, Huber R, Esser SK, Singh H, Tononi G (2005) Breakdown of cortical effective connectivity during sleep. Science 309: 2228-2232. CrossRef Medline

Mumford D (1992) On the computational architecture of the neocortex: II. The role of cortico-cortical loops. Biol Cybern 66:241-251. CrossRef Medline

Näätänen R, Alho K (1995) Mismatch negativity: a unique measure of sensory processing in audition. Int J Neurosci 80:317-337. CrossRef Medline

Näätänen R, Paavilainen P, Tiitinen H, Jiang D, Alho K (1993) Attention and mismatch negativity. Psychophysiology 30:436-450. CrossRef Medline

Näätänen R, Kujala T, Winkler I (2011) Auditory processing that leads to conscious perception: a unique window to central auditory processing opened by the mismatch negativity and related responses. Psychophysiology 48:4-22. CrossRef Medline

Nagahama Y, Kovach CK, Ciliberto M, Joshi C, Rhone AE, Vesole A, Gander PE, Nourski KV, Oya H, Howard MA 3rd, Kawasaki H, Dlouhy BJ (2018) Localization of musicogenic epilepsy to Heschl's gyrus and superior temporal plane: case report. J Neurosurg 129:157-164. CrossRef Medline

Nelson LE, Guo TZ, Lu J, Saper CB, Franks NP, Maze M (2002) The sedative component of anesthesia is mediated by GABA(A) receptors in an endogenous sleep pathway. Nat Neurosci 5:979-984. CrossRef Medline

Nir Y, Vyazovskiy VV, Cirelli C, Banks MI, Tononi G (2015) Auditory responses and stimulus-specific adaptation in rat auditory cortex are preserved across NREM and REM sleep. Cereb Cortex 25:1362-1378. CrossRef Medline

Nourski KV (2017) Auditory processing in the human cortex: an intracranial electrophysiology perspective. Laryngoscope Investig Otolaryngol 2:147-156. CrossRef Medline 
Nourski KV, Steinschneider M, McMurray B, Kovach CK, Oya H, Kawasaki H, Howard MA 3rd (2014) Functional organization of human auditory cortex: investigation of response latencies through direct recordings. Neuroimage 101:598-609. CrossRef Medline

Nourski KV, Howard MA 3rd (2015) Invasive recordings in the human auditory cortex. Handb Clin Neurol 129:225-244. CrossRef Medline

Nourski KV, Banks MI, Steinschneider M, Rhone AE, Kawasaki H, Mueller RN, Todd MM, Howard MA 3rd (2017) Electrocorticographic delineation of human auditory cortical fields based on effects of propofol anesthesia. Neuroimage 152:78-93. CrossRef Medline

Nourski KV, Steinschneider M, Rhone AE, Kawasaki H, Howard MA 3rd, Banks MI (2018) Processing of auditory novelty across the cortical hierarchy: an intracranial electrophysiology study. Neuroimage. Advance online publication. Retrieved Aug. 13, 2018. doi: 10.1016/j.neuroimage.2018.08.027. CrossRef Medline

Plourde G, Belin P, Chartrand D, Fiset P, Backman SB, Xie G, Zatorre RJ (2006) Cortical processing of complex auditory stimuli during alterations of consciousness with the general anesthetic propofol. Anesthesiology 104:448-457. CrossRef Medline

Portas CM, Krakow K, Allen P, Josephs O, Armony JL, Frith CD (2000) Auditory processing across the sleep-wake cycle: simultaneous EEG and fMRI monitoring in humans. Neuron 28:991-999. CrossRef Medline

Rao RP, Ballard DH (1999) Predictive coding in the visual cortex: a functional interpretation of some extra-classical receptive-field effects. Nat Neurosci 2:79-87. CrossRef Medline

Raz A, Grady SM, Krause BM, Uhlrich DJ, Manning KA, Banks MI (2014) Preferential effect of isoflurane on top-down versus bottom-up pathways in sensory cortex. Front Syst Neurosci 8:191. CrossRef Medline

Reddy CG, Dahdaleh NS, Albert G, Chen F, Hansen D, Nourski K, Kawasaki H, Oya H, Howard MA 3rd (2010) A method for placing Heschl gyrus depth electrodes. J Neurosurg 112:1301-1307. CrossRef Medline

Rudolph U, Antkowiak B (2004) Molecular and neuronal substrates for general anaesthetics. Nat Rev Neurosci 5:709-720. CrossRef Medline

Sanders RD, Tononi G, Laureys S, Sleigh JW (2012) Unresponsiveness not equal unconsciousness. Anesthesiology 116:946-959. CrossRef Medline

Sergent C, Baillet S, Dehaene S (2005) Timing of the brain events underlying access to consciousness during the attentional blink. Nat Neurosci 8:1391-1400. CrossRef Medline
Shushruth S (2013) Exploring the neural basis of consciousness through anesthesia. J Neurosci 33:1757-1758. CrossRef Medline

Simpson TP, Manara AR, Kane NM, Barton RL, Rowlands CA, Butler SR (2002) Effect of propofol anaesthesia on the event-related potential mismatch negativity and the auditory-evoked potential N1. Br J Anaesth 89:382-388. CrossRef Medline

Steinschneider M, Fishman YI, Arezzo JC (2008) Spectrotemporal analysis of evoked and induced electroencephalographic responses in primary auditory cortex (A1) of the awake monkey. Cereb Cortex 18:610-625. CrossRef Medline

Strauss M, Sitt JD, King JR, Elbaz M, Azizi L, Buiatti M, Naccache L, van Wassenhove V, Dehaene S (2015) Disruption of hierarchical predictive coding during sleep. Proc Natl Acad Sci U S A 112:E1353-E1362. CrossRef Medline

Tononi G, Boly M, Massimini M, Koch C (2016) Integrated information theory: from consciousness to its physical substrate. Nat Rev Neurosci 17:450-461. CrossRef Medline

Uhrig L, Janssen D, Dehaene S, Jarraya B (2016) Cerebral responses to local and global auditory novelty under general anesthesia. Neuroimage 141: 326-340. CrossRef Medline

Vanluchene AL, Struys MM, Heyse BE, Mortier EP (2004) Spectral entropy measurement of patient responsiveness during propofol and remifentanil: a comparison with the bispectral index. Br J Anaesth 93:645-654. CrossRef Medline

Viertiö-Oja H, Maja V, Särkelä M, Talja P, Tenkanen N, Tolvanen-Laakso H, Paloheimo M, Vakkuri A, Yli-Hankala A, Meriläinen P (2004) Description of the Entropy algorithm as applied in the Datex-Ohmeda S/5 Entropy Module. Acta Anaesthesiol Scand 48:154-161. CrossRef Medline

Wilf M, Ramot M, Furman-Haran E, Arzi A, Levkovitz Y, Malach R (2016) Diminished auditory responses during NREM sleep correlate with the hierarchy of language processing. PLoS One 11:e0157143. CrossRef Medline

Zhang Z, Ferretti V, Güntan I, Moro A, Steinberg EA, Ye Z, Zecharia AY, Yu X, Vyssotski AL, Brickley SG, Yustos R, Pillidge ZE, Harding EC, Wisden W, Franks NP (2015) Neuronal ensembles sufficient for recovery sleep and the sedative actions of alpha2 adrenergic agonists. Nat Neurosci 18: 553-561. CrossRef Medline 